\title{
Development of a model to predict the Shear force of a horizontal mechanical digester
}

\author{
Sunday Reagan Ogblechi, ${ }^{1,}$, Moses Toye $\operatorname{Ige}^{2}$ \\ ${ }^{1}$ Nigerian Institute for Oil Palm Research (NIFOR), Agricultural Engineering Research Division, P. M. B 1030, Benin City, Edo State, \\ Nigeria \\ ${ }^{2}$ Obafemi Awolowo University, Department of Agricultural \& Environmental Engineering, Faculty of Technology, Ile - Ife, Osun State, \\ Nigeria
}

\section{Email address:}

ogblechs@yahoo.com (S. R. Ogblechi), mosesige63@yahoo.com (M. T. Ige)

\section{To cite this article:}

Sunday Reagan Ogblechi, Moses Toye Ige. Development of a Model to Predict the Shear Force of a Horizontal Mechanical Digester. International Journal of Science, Technology and Society. Vol. 2, No. 6, 2014, pp. 174-178. doi: 10.11648/j.ijsts.20140206.12

\begin{abstract}
A model to predict the shearing/crushing force of an existing horizontal mechanical digester used for pulverization/digestion or maceration of date palm fruit was developed in the study. The model accurately predicted the shearing force used in digestion of fruit with model simulation done using Matlab 7.9 (R2009b). The results obtained showed a linear relationship between shearing force and angular velocity of implements/beater arms which are components of the digester that did the shearing of fruit mesocarp. It was also observed from results obtained that the higher the magnitude of angular velocity of shearing implement the higher the magnitude of shearing force of the digester. An angular velocity of 15.71 $\operatorname{rads}^{-1}$ yielded a shear force of $400.00 \mathrm{kN}$ with an angular velocity of $34.56 \mathrm{rads}^{-1}$ yielding a shear force of $880.00 \mathrm{kN}$. It was reported by the literary world that high magnitude of shear force is more efficient in pulverization process than shear force of low magnitude.
\end{abstract}

Keywords: Model, Force, Horizontal Mechanical Digester, Pulverization, Fruit Mesocarp, Linear, Angular Velocity, Efficient

\section{Introduction}

A horizontal mechanical digester is an equipment that is used to pulverize the mecsocarp of either sterilized/cooked or uncooked agricultural crops into minute particles for the purpose of further processing [1] and [2]. This device is usually cylindrical in shape with a centrally located shaft [3] and [4]. The shaft carries some beater arms which are used for the purposes of comminuting and transporting biomaterials.

Mechanical digester comes in two categories and these are vertical and horizontal digesters. In a vertical digester comminution (digestion) of fruit mesocarp is done by a vertical shaft fitted with beater arms at specified orientation and spacing on the shaft. A horizontal digester as the name implies has a horizontal shaft with beater arms at specified orientation and spacing. Comminution of biomaterials is done by the beater arms which also transport comminuted biomass from digester inlet to the outlet.

Biomass utilization for bio-based products, bio-fuel and bio-energy requires size reduction to meet the need for further processing [12]. Mechanical size reduction of biomaterials is a cutting or comminution process that significantly transform particle size, bulk density and shape of materials. Rotary equipment such as horizontal digester, hammer mill, disc and knife mills carry out comminution process in various ways by utilizing the physical and mechanical properties of the materials, tools geometry, dynamic of separation and particles feeding rate [12]. The need to achieve the desired outcomes at minimal cost and time in material processing call for the optimization of materials processing.

In this study, the shear force required for the comminution or pulverization of date palm fruit mesocarp was determined. The pulverization process is responsible for the breaking-up of nutrient bearing cell of sterilized date palm fruit mesocarp. When the nutrient bearing cell is broken up, embedded nutrients within the cell will be released by the application of pressure [1]. 


\section{Materials}

The materials used in the study were as follows.

Raw materials: Dry date palm fruits were obtained from Nigerian Institute for Oil Palm Research (NIFOR), Date Palm Substation, Dogon-Dutse, Jigawa State, Nigeria.

\subsection{Equipment}

(i) An existing horizontal mechanical digester: This is used for the comminution or digestion of date palm fruit after appropriate fruit treatment such as sterilization by steaming. The digester is represented by Fig. 1.

(ii) Prime mover:_This is an 8 horse power diesel engine used as a prime mover to drive the digester.

(iii) Steaming vessel: The item (Plate 1) is made up of stainless steel materials with the incorporation of a burner of mild steel origin to provide the necessary heat for steaming operations. It was used to hydrate dry date palm fruit using steam at atmospheric pressure so as to facilitate the maceration/comminution of the fruit mass. Digestion of the fruit promotes solubilization of the nutrient components of the fruit.

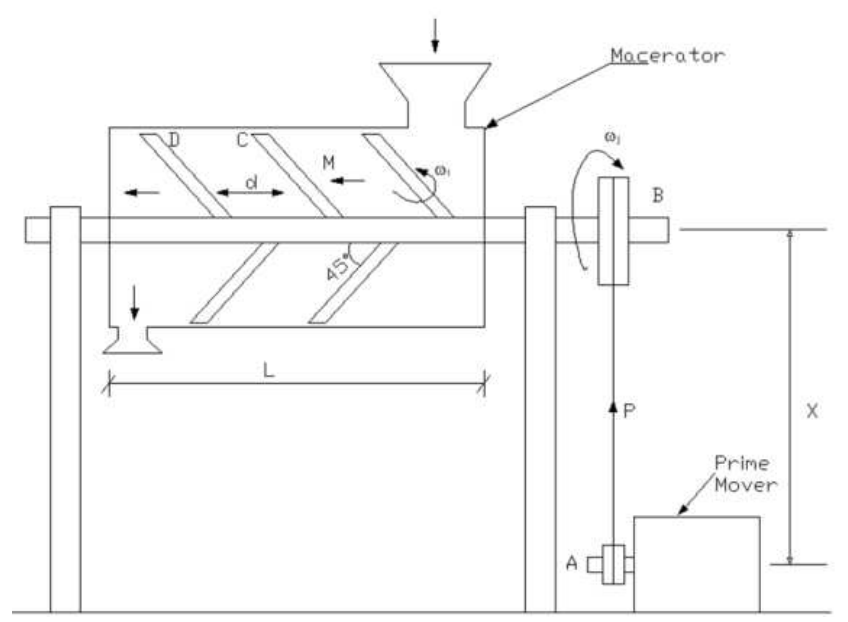

Fig. 1. Physical model of the digester.

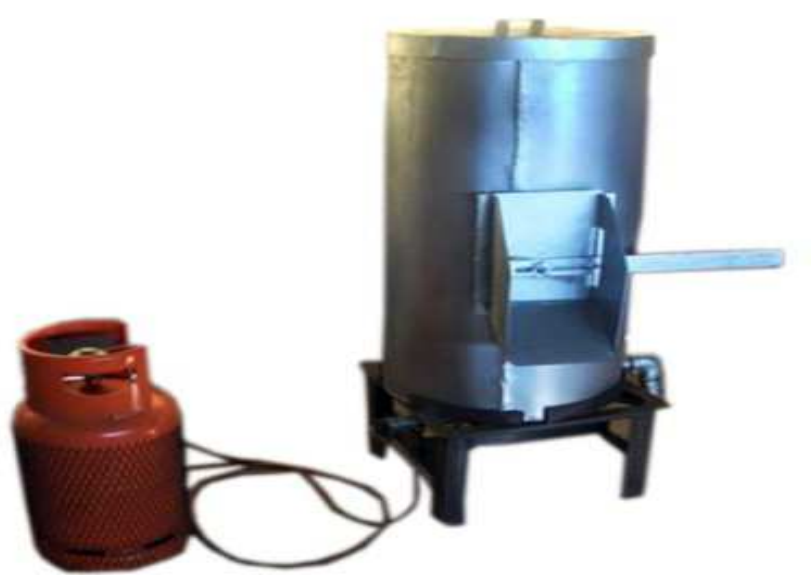

Plate 1. Steaming vessel

\subsection{Instrumentation}

(i) Digital weighing balance:_A weighing balance of a maximum mass of $15 \mathrm{~kg}$ with a precision of $0.001 \mathrm{~g}$ was used for the determination of mass.

(ii) Thermometer: A digital temperature probe with a range of $-50{ }^{\circ} \mathrm{C}$ to $750{ }^{\circ} \mathrm{C}$ was used for temperature determination. The make was a k-type, Mastech, Ms 6500 .

(iii) Tachometer: This is a microprocessor digital tachometer and a photo/contact type with a serial No. Lutron DT2236B was used to determine the speed of machine shaft and the prime mover in revolution per minute (rpm).

(iv) Stopwatch: This was used for recording time of experimental runs.

\section{Method}

A model to predict the shearing force of an existing horizontal mechanical digester is here developed. The shearing force is the force responsible for the comminution of fruit mesocarp when the digester is in operation. Torque is developed by the action and reaction of prime mover and digester when the digester is charged with fruit mass. The torque generated was determined by taking the moment of forces at some points of actions [5] and [6]. The shear force was then obtained from the torque developed. Fig. 1 is the physical model of the digester. The model developed was used to predict the effect of shear force on angular velocity.

\subsection{Derivation of Equations}

The digester was driven by a prime mover which is an 8 horse power diesel engine. Force for maceration of steamtreated date palm fruit is transmitted from the prime mover to the macerator by means of a $144 \mathrm{~V}$-belt and a $150 \mathrm{~mm}$ diameter pulley. The following assumptions were made in the determination of the torque developed.

\subsection{Assumptions Made for Torque Determination}

(i) Moment of a force at a point of action $=0$.

(ii) Sum of moments of forces $=0$.

(iii) Sum of moments of forces $=$ torque.

(iv) No radial movement of particles.

The moment of forces at point A in Fig. 1 is given as "(1)".

$$
\mathrm{P}_{\mathrm{w}} X \frac{\partial \theta}{\partial \omega_{j}}=0
$$

where $\mathrm{P}_{\mathrm{w}}=$ power generated by prime mover (kilowatts),

$\mathrm{X}=$ distance upon which moment was taken (metres),

$\omega_{j}=$ angular velocity of beater arm in $j$-direction (rads per second),

$\theta=$ angle of inclination of beater arm to digester shaft (radians),

$\frac{\partial \theta}{\partial \omega_{j}}=$ change in angular speed in $j$ - direction. 
The moment of forces at point $\mathrm{C}$ in Fig. 1 is given as "(2)".

$$
M d \frac{\partial \theta}{\partial \omega_{i}}=0,
$$

where $\mathrm{M}=$ mass of fruit $(\mathrm{Kg})$,

$\mathrm{d}=$ distance moved by fruit (metres),

$\omega_{i}=$ angular velocity in $i$ - direction (rads per second).

The torque developed by the digester/macerator is the sum of the moments of forces in "(1)" and "(2)" which is given as "(3)". "Equation (3) is then solved by differentiation, integration and substitution coupled with the application of boundary conditions to obtain the torque developed".

$$
\text { Torque }=\tau=\mathrm{P}_{\mathrm{w}} X \frac{\partial \theta}{\omega_{j}}+M d \frac{\partial \theta}{\partial \omega_{i}},
$$

Initial conditions: $\omega_{j}, \omega_{i}=0, \tau=0$.

\subsection{Solution to the Derived Equation}

The method of characteristics for solving partial differential equations [7], [8] and [9] was adopted in solving the derived equation "(3)".

Divide "(3)" by $\mathrm{P}_{\mathrm{w}} \mathrm{X}$ to give "(4)".

$$
\frac{\tau}{\mathrm{P}_{\mathrm{w}} \mathrm{X}}=\frac{\partial \theta}{\partial \omega_{j}}+\frac{M d}{\mathrm{P}_{\mathrm{w}} X} \frac{\partial \theta}{\partial \omega_{i}} \text {. }
$$

Using the method of characteristics to solve "(4)", the systems of ordinary differential equations are given as follows:

Given that

$$
\frac{d \theta}{d \omega_{j}}=\frac{\tau}{\mathrm{P}_{\mathrm{w}} \mathrm{X}^{\prime}}
$$

and from

$$
\frac{d \theta}{d \omega_{j}}=\frac{d \theta}{d \omega_{i}} \frac{d \omega_{i}}{d \omega_{j}}+\frac{d \theta}{d \omega_{j}},=\frac{d \theta}{d \omega_{j}}+\frac{M d}{\mathrm{P}_{\mathrm{w}} \mathrm{X}} \frac{d \theta}{d \omega_{i}},
$$

hence,

$$
\frac{d \omega_{i}}{d \omega_{j}}=\frac{M d}{\mathrm{P}_{\mathrm{w}} X}
$$

From "(5)", $d \theta=\frac{\tau}{\mathrm{P}_{\mathrm{w}} \mathrm{X}} d \omega_{j}$,

Integrating both sides,

$$
\int d \theta=\int \frac{\tau}{\mathrm{P}_{\mathrm{w}} \mathrm{X}} d \omega_{j}, \theta\left(\omega_{j}\right)=\frac{\tau}{\mathrm{P}_{\mathrm{w}} \mathrm{X}} \omega_{j}+\omega_{j}(0) .
$$

From “(6)”,

$$
d \omega_{i}=\frac{M d}{\mathrm{P}_{\mathrm{w}} X} d \omega_{j}
$$

From “(7)"

$$
\theta\left(\omega_{j}\right)-\omega_{j}(0)=\frac{\tau}{\mathrm{P}_{\mathrm{w}} \mathrm{X}} \omega_{j}, \frac{\mathrm{P}_{\mathrm{w}} \mathrm{X}}{\tau}\left[\theta\left(\omega_{\mathrm{j}-} \omega_{j}(0)\right)\right]=\omega_{j}
$$

Substituting “(9)" in “(8)" gives “(10)”.

$$
d \omega_{i}=\frac{M d}{\mathrm{P}_{\mathrm{w}} \mathrm{X}} d\left[\frac{\mathrm{P}_{\mathrm{w}} \mathrm{X}}{\tau}\left(\theta\left(\omega_{j}\right)-\omega_{j(0)}\right)\right] .
$$

Integrating “(10)” as follows:

$$
\begin{aligned}
& \int d \omega_{i}=\int\left\{\frac{M d}{\mathrm{P}_{\mathrm{w}} \mathrm{X}} d\left[\frac{\mathrm{P}_{\mathrm{w}} \mathrm{X}}{\tau}\left(\theta\left(\omega_{j}\right)-\omega_{j(0)}\right)\right]\right\}, \\
& \omega_{i}=\frac{M d}{\tau}\left[\theta\left(\omega_{j}-\omega_{j}(0)\right)\right], \\
& \tau=\frac{M d}{\omega_{i}}\left[\theta\left(\omega_{j}-\omega_{j}(0)\right)\right],
\end{aligned}
$$

Applying boundary conditions:

$$
\begin{gathered}
\omega_{j}, \omega_{i}=0, \quad \tau=0, \\
\theta\left(\omega_{j}, \omega_{i}\right)=f(0), \\
\theta\left(\omega_{j}\right)=\theta_{j} . \\
\tau=\frac{M d}{\omega_{i}} \theta\left(\omega_{j}\right)=\frac{M d}{\omega_{i}} \theta_{j}
\end{gathered}
$$

Note that Shear force $\left(\mathrm{S}_{\mathrm{f}}\right)=\frac{1}{\text { Torque }(\tau)^{\prime}}$,

Hence, from (12),

$$
S_{f}=\frac{\omega_{i}}{M d \theta_{j}}
$$

"Equation (12) is the torque developed while the inverse of the torque is the shear force $\left(S_{f}\right)$ of the macerator/digester given by "(13)" which is the shear force model". The model was validated using Matlab 7.9 (R2009b) with the following being the model parameters.

$\mathrm{M}=$ mass of biomass $(\mathrm{kg})$,

$\mathrm{d}=$ distance between beater arms (metre),

$\omega_{i}=$ angular velocity of beater arm in $i$ - direction (rads per second),

$\theta_{j}=$ angle of rotation (radians), $\omega_{i}=\frac{\pi N_{i}}{30}$,

$N_{i}=$ revolution per minute $(\mathrm{rpm})$ in $i$-direction.

$$
\text { Angular velocity }=\frac{\pi N}{30} \text {. }
$$

Note that $\mathrm{N}_{1} \mathrm{D}_{1}=\mathrm{N}_{2} \mathrm{D}_{2}$,

where $\mathrm{N}, \mathrm{N}_{1}$ and $\mathrm{N}_{2}=$ revolution per minute,

$D_{1}$ and $D_{2}=$ either diameter of shaft or pulley,

Power $(\mathrm{P})=$ Torque $(\hat{\mathrm{o}}) \times$ Angular velocity $(\grave{\mathrm{u}}),(15)$

$$
\begin{gathered}
\text { Torque }(\hat{\mathrm{o}})=\frac{\text { Power }\left(\mathrm{P}_{\mathrm{w}}\right)}{\text { Angular velocity }(\grave{\mathrm{u}})}, \\
\text { Torque }(\hat{\mathrm{o}})=\text { Force } \times \text { distance, }
\end{gathered}
$$

$$
\text { Pressure }=\frac{\text { Force }}{\text { Area }} \text {. }
$$




\section{Results and Discussion}

A shear force model was developed in the study and the model is given as "(13)" with definition of model parameters accordingly. The model was used to predict the shear force of an existing horizontal mechanical digester that is used for comminution of sterilized date palm fruit. It was observed that shear force depends principally on the speed of rotating shaft that carries the beater arms involved in pulverization of fruit mesocarp. The rotational speed of the digester shaft gave rise to angular speed (speed of pulverization) of the beater arms that performed the digestion of fruit mesocarp.

Table 1 shows results obtained from the simulation of the shear force model by inputing some values for mass, distance between beater arm, angle of pulverization (angle between beater arm and digester shaft) and angular speed of comminution (velocity of beater arm). The result showed that varying angular speed with factors such as fruit mass, distance between beater arm and angle of pulverization gave rise to a linear relationship between angular speed and shear force. That is an increase in angular velocity (speed of pulverization) gave rise to a corresponding increase in shearing force while a decrease in angular velocity gave a corresponding decrease in shearing force [2] and [10]. Fig. 2 and Table 1 clearly showed the linear relationship between shearing/crushing force and angular velocity. Statistical analysis using Microsoft excel gave coefficient of variation $\left(\mathrm{R}^{2}\right)$ of 1 between shear force and angular speed.

Table 1. Shearing Force at Varying Shaft Speed.

\begin{tabular}{|c|c|c|c|c|c|c|c|}
\hline S/No & $\begin{array}{l}\text { Distance } \\
\text { between each } \\
\text { beater arm (m) }\end{array}$ & $\begin{array}{l}\text { Mass of fruit } \\
\text { (kg) }\end{array}$ & $\begin{array}{l}\text { Angle of beater arm } \\
\text { to digester shaft } \\
\text { (degrees) }\end{array}$ & $\begin{array}{l}\text { Angle of beater } \\
\text { arm to digester } \\
\text { shaft (radians) }\end{array}$ & $\begin{array}{l}\text { Speed }\left(\mathrm{N}_{\mathrm{i}}\right) \text { of } \\
\text { beater } \text { arm } \\
(\mathrm{rpm})\end{array}$ & $\begin{array}{l}\text { Angular speed }\left(\mathrm{u}_{i}\right) \\
\text { of } \\
\text { beater } \operatorname{arm}\left(\mathrm{rads}^{-1}\right)\end{array}$ & $\begin{array}{l}\text { Shear force } \\
\text { generated } \\
(\mathbf{k N})\end{array}$ \\
\hline 1. & 0.05 & 1 & $45^{\circ}$ & 0.78540 & 150 & 15.70796 & 400.00 \\
\hline 2. & 0.05 & 1 & $45^{\circ}$ & 0.78540 & 170 & 17.80236 & 453.33 \\
\hline 3. & 0.05 & 1 & $45^{\circ}$ & 0.78540 & 190 & 19.89675 & 506.67 \\
\hline 4. & , & , & , & , & 210 & 21.99115 & 560.00 \\
\hline 6. & , & " & , & , & 250 & 26.17994 & 666.67 \\
\hline 7. & , & , & , & , & 270 & 28.27433 & 720.00 \\
\hline 8. & " & , & , & , & 290 & 30.36873 & 773.33 \\
\hline 9. & ", & , & " & " & 310 & 32.46312 & 826.67 \\
\hline 10. & , & , & , & , & 330 & 34.55752 & 880.00 \\
\hline
\end{tabular}

The working principle of the mechanical digester is synonymous with the principle of a hammer mill which depends on high speed for efficient shearing and shredding of materials into fine particles. A high speed implement involved in a pulverization process generate high cutting speed which is more efficient as applicable in digesters and shredders [6]. Drivers of high cutting speed equipment usually developed low torque when compared to low cutting speed equipment which is associated with high torque [6]. It could therefore, be said that the higher the speed of the rotating shaft carrying the beater arms of the digester the more efficient is the digestion process.

Modelling materials processing enable prediction of material and process behaviours at a particular time in a specified domain. In a study by [11] on "Modelling the Comminution Energy Requirements of Two Hard Nut Shells by Hammer Milling" predicted optimum energy requirements for milling palm kernel and coconut shells in a hammer mill. Another study by [12] on "Analysis of Biomass Comminution and separation processes in Rotary Equipment-A Review" gave a comprehensive detail on machines design and process investigation that related to material properties as well as requirements for further mechanical and bio-chemical processing. As a backup from the two studies enumerated, size reduction in biomass processing cannot be avoided since it paves ways for sophisticated handling of agricultural produce and optimum output of agricultural products .

\section{Conclusion}

Fundamental modelling approach was employed in the study for the development of a shear force model which accurately predicted the shear force of an existing horizontal mechanical digester. Equations from which the shear force model was obtained were derived from the torque generated by the prime mover that drives the digester coupled with the actions and reactions of forces when the digester is in operation. Some assumptions were made in order to take accurate moment of forces that gave the appropriate equations which were solved to give the shear force model. Data analysis using Microsoft excel gave an $\mathrm{R}^{2}$ of 1 between shear force and angular speed as been shown by the linearity of Fig. 2. The shear force model is giving as "(13)".

The shear force model could be used to predict the magnitude of crushing forces of mechanical digesters which could either be horizontal or vertical if the input variables are known. This model could also act as a guide for the design and development of efficient mechanical digesters needed for optimum pulverization or comminution of agricultural produce which will also minimize the quantities of materials used in the development of mechanical digesters as a result of the optimization exercise carried out in the study. 


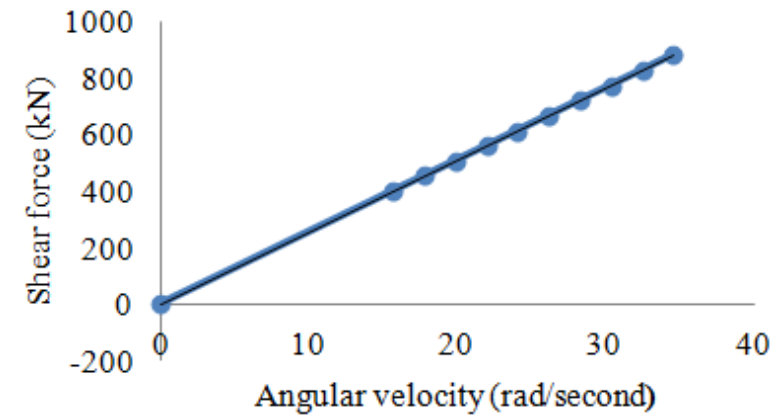

Fig. 2. Effect of angular velocity on shear force of a mechanical digester.

\section{References}

[1] Corley, R. H. V. and Tinker, P. B. (2003): The oil palm. World Agricultural Series. Published by Blackwell science Ltd., pp $454-457$.

[2] Serpil, S. and Servet, G. S. (2006): Physical properties of foods. Springer, pp 39-46.

[3] Badmus, G. A. (1981): The horizontal digester-design, fabrication and testing. Proceedings of Nigerian society of agricultural engineers, pp 137-154.

[4] Ilechie, C. O. and Omoti, U. (2003): Small-scale oil palm fruit processing in Nigeria. Journal of palms and oil seeds. 15: pp 66-73.
[5] Hannah, J and Stephens, R. C. (1973): Mechanics of machines, elementary theory and examples, S.I units, third edition. pp 108-134.

[6] Khurmi, R. S. and Gupta, J. K. (2010): A textbook of machine design. Eurasia publishing house (PVT.) Ltd., New Delhi, pp 53-86, pp 120-180, pp 181-223 and pp 509-557.

[7] Alan, J. (2002): Advanced engineering mathematics, Harcourt/academic press, pp 242-250, 934-942.

[8] Chan Man Fong, C. F., De Kee, D. and Kaloni, P. N. (2003):Advanced mathematics for engineers and science, World scientific publishing company, pp 402-420.

[9] Stroud, K. A. and Dexter, J. B. (2003): Advanced engineering mathematics, $4^{\text {th }}$ edition, Palgrave Macmillan, pp 414-419.

[10] Mohsenin, N. N. (1978): Physical properties of plant and animal materials. Structure, physical characteristics and mechanical properties. Gordon and Beach science publishers. pp 558-593.

[11] Kayode, olakunle and Koya, Olufemi A. (2013): Modelling the comminution energy requirements of two hard nut shells by hammer milling. International journal of research in engineering and technology, vol., 2, no., 5

[12] Petre I. Miu, Alvin R. Woma, Igathinathane Cannayen, Shahab Sokhansanj (2006): Analysis of biomass comminution and separation processes in rotary equipment-a review. American Society of Agricultural and Biological Engineers, 2006 annual meeting, paper no.066169. 